\title{
Measurement of small-bowel polyp size in patients with Peutz-Jeghers syndrome by using reference granules during video capsule endoscopy
}

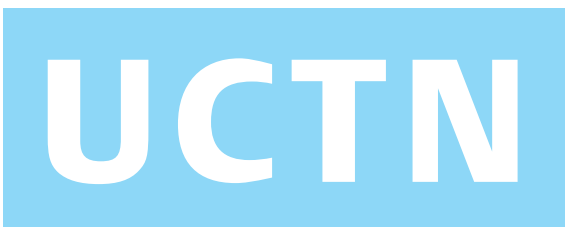

In patients with Peutz-Jeghers syndrome, capsule endoscopy is a promising method of surveillance to detect the larger polyps that are most relevant clinically $[1,2]$. However, to our knowledge there is no formal method of judging polyp size accurately during capsule endoscopy [3]. Inaccurate assessment of polyp sizes has important implications for management [4].

To increase the accuracy of polyp size assessment in patients with Peutz-Jeghers syndrome, we devised a polyp-diametermeasuring method by using reference size granules during video capsule endoscopy. Patients with Peutz-Jeghers syndrome who were undergoing capsule endoscopy ingested one sachet of Salofalk ${ }^{\circledast}$ Granu-Stix ${ }^{\circledR} 5$ minutes before swallowing the video capsule. Each sachet contained 600 granules, each with a diameter of $1 \mathrm{~mm}$ (Figure $\mathbf{1}$ ).

Both video capsule and granules were propelled close to each other by small bowel peristalsis. In most of the images, therefore, granules were seen and could be used as a reference size device. Granules dissolved in the distal part of the ileum, and they did not disturb the quality of images.

We used a simple mathematical equation to avoid inaccuracy in measuring actual sizes, which may result from the difficulty in judging the distance of both the polyps and reference size granules from the capsule. First we measured, one by one, the diameter of 80-100 granules seen on the video images, and the mean apparent granule size was calculated (Ga). Then we calculated the real polyp sizes (Pr) by using the apparent polyp diameters ( $\mathrm{Pa}$ ) measured on the image screen: $\mathrm{Pr}=\mathrm{Pa} / \mathrm{Ga}$.

Using this mathematical model of continual approaches, one can calculate the real size of any polyp independently, whether or not the polyp is seen together with granules on the same image (Figure 2 ).

We tested our method successfully in three patients with Peutz-Jeghers syn-

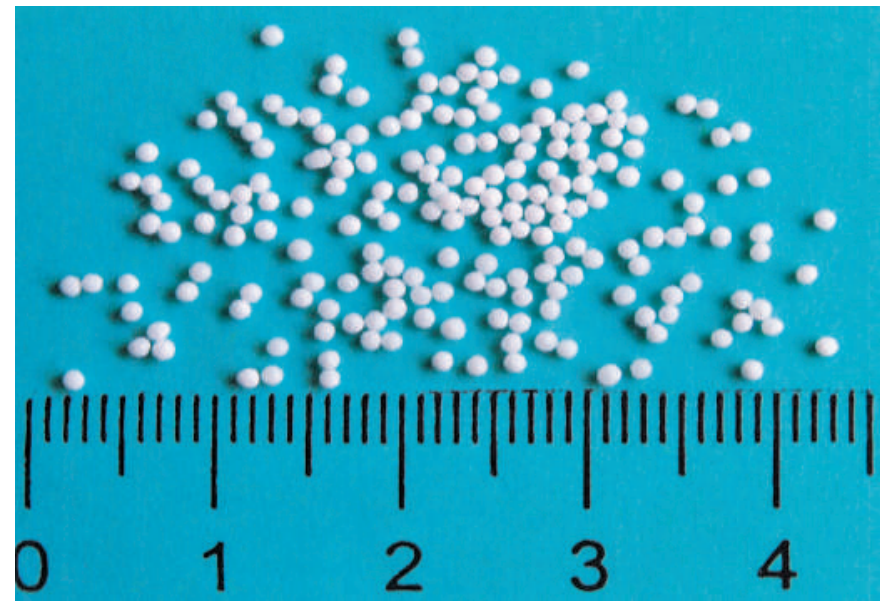

Figure 1 Reference size granulas each with $1 \mathrm{~mm}$ diameter.
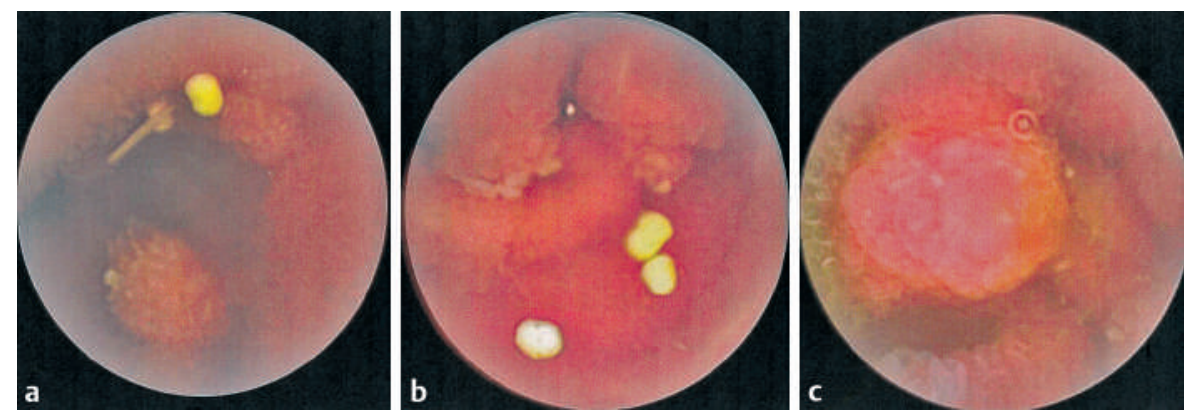

Figure 2 Jejunal polyps observed in patient with Peutz-Jeghers polyposis. Reference size granules are close to the polyps (a, b). The calculated polyp sizes are 2.4 and $4.3 \mathrm{~mm}$ (a), and 3.8 and $4.4 \mathrm{~mm}$ (b), and $6.5 \mathrm{~mm}$ (c) at the highest diameters.

drome. Polyp sizes of those removed by enteroscopy matched precisely the polyp sizes calculated by our method.

Endoscopy_UCTN_Code_CCL_1AC_2AC Endoscopy_UCTN_Code_TTT_1AP_2AB

\section{Rácz, M. Jánoki, V. Kovács}

$1^{\text {st }}$ Department of Internal Medicine and Gastroenterology, Petz Aladár County and Teaching Hospital, Győr, Hungary.

\section{References}

${ }^{1}$ Parsi MA, Burke CA. Utility of capsule endoscopy in Peutz-Jeghers syndrome. Gastrointest Endos Clin N Am 2004; 14: 159-167

2 Soares J, Lopes L, Vilas Boas G, Pinho C. Wireless capsule endoscopy for evaluation of phenotypic expression of small-bowel polyps in patients with Peutz-Jeghers syndrome and symptomatic first-degree relatives. Endoscopy 2004; 36: 1060 - 1066

3 Brown G, Fraser C, Scholfield G et al. Video capsule endoscopy in Peutz-Jeghers syn- drome: a blinded comparison with barium follow-through for detection of small-bowel polyps. Endoscopy 2006; 38: $385-390$

${ }^{4}$ Caspari R, von Falkenhausen M, Krautmacher $\mathrm{C}$ et al. Comparison of capsule endoscopy and magnetic resonance imaging for the detection of polyps of the small intestine in patients with familial adenomatous polyposis or with Peutz-Jeghers' syndrome. Endoscopy 2004; 36: $1054-1059$

\section{Corresponding author}

\section{Rácz, MD}

$1^{\text {st }}$ Department of Internal Medicine and Gastroenterology

Petz Aladár County and Teaching Hospital Győr · Vasvári Pál u. 2 · 9024 Győr · Hungary

Fax: $\quad+36-96-418-486$

Email: raczi@petz.gyor.hu

DOI: $10.1055 / \mathrm{s}-2006-945063$ 